\title{
Tracking the creativity cycle with a microcomputer
}

\author{
Mildred L. G. Shaw and Brian R. Gaines \\ Centre for Man-Computer Studies, 92 Shakespeare Tower, Barbican, \\ London EC2Y 8DR, UK.
}

\begin{abstract}
One of the major attractions of introducing electronic technology in education has been that of providing individualized instruction. However, it has proved very difficult to obtain a representation of each student's inferred knowledge state on which to base such individualization. In this paper we present Kelly's personal construct psychology as a framework for the analysis of the educational process and educational system, and particularly for the practical determination of relevant features of the knowledge state. His notions of constructive alternativism, and the creativity cycle in particular, are both of major theoretical significance and can also be studied through interactive microcomputer programs eliciting the construct systems of students and teachers.
\end{abstract}

\section{Introduction}

One of the major attractions of introducing electronic technology in education has become that of providing individualized instruction (Suppes, 1967). One can see the shift in emphasis from simple automation to improved education through such individualization in Lumsdaine \& Glasers' (1960) presentation of a sequence of key historic papers on Teaching Machines and Programmed Learning covering the period 1924-1959, and Galanter's (1959) symposium on Automatic Teaching: The State of the Art at the end of that period. They commence with Pressey's original teaching machines of 1924 and his discussion of "the coming 'industrial revolution' in education" (Lumsdaine \& Glaser, 1960, p. 47) which will result in "freeing the teacher from the drudgeries of her work". Thirty-five years later Galanter $(1959$, p. 4) is looking for a machine that will "be able to make plans for itself, and also able to diagnose the plans and ideas that the student has formed".

As programmed learning became computer aided instruction (CAI) this requirement for individualization became more realistic to achieve. However, the difficulties also became apparent of developing systems to model the learner, his plans and ideas. Gaines (1978, p. 227) noted that "computer-based instruction was over-sold a decade ago. The computer was going to bring new freedom into education by individualized instruction, tailoring it to the personal needs of the student" and points to the paucity of information available to the computer about the student in asking "are we surprised not to have achieved it?". Such considerations led to Bunderson's (1974) development of learner managed instruction in which the user rather than the computer controlled the individualization. It also has led to the adoption of the more neutral term computer assisted learning (CAL) for the variety of roles in which the computer may be used in education, most of which do not assume that the computer can be programmed to model the learner.

During the past five years, reductions in the cost of microelectronics have made it feasible to introduce microcomputers into schools and the machines available now have greater processing and storage power than those originally used in CAI research 
some 15 years ago. Already these low-cost machines are being used effectively in CAL for many courses (Tagg, 1980; P. Smith, 1981) and further reductions in cost will see their use spread through all areas of the curricula. However, the individualization of computer assisted learning through information gained through the computer interaction itself is still problematic. As Mitchell $(1981$, p. 64) emphasizes, it requires "a representation of each student's inferred knowledge state" and this is very different from "a list of behaviors".

Research on knowledge representation in studies of artificial intelligence (Bobrow \& Collins, 1975; Fahlmann, 1979), and particularly that on expert systems (Michie, 1979), has led to a far greater understanding in recent years of the processes necessary to represent knowledge structures. The magnitude of the problems involved in matching the skills involved in the performance of a task, let alone those of learning it, emphasize the gap between our early aspirations for individualized instruction and the methods available to us for achieving it. Artificial intelligence techniques are now making significant contributions to CAL programs (Sleeman \& Brown, 1982) but the problem remains of measuring even part of the knowledge structure of the student given the limited information available from the student-computer interaction. In most circumstances we have to assume that the computer can never have more than a very limited representation of the student and the question arises as to what are the key components of that partial representation.

In this paper we suggest that Kelly's model of a person's knowledge being based on a set of personal constructs that are "templets which he creates and then attempts to fit over the realities of which the world is composed" (Kelly, 1955, p. 9) gives the key to those aspects of the student that we need to represent in the computer. If we can represent the individual construct system and track its changing structure as the student learns then we have the basis for individualizing educational material in CAL.

We have previously developed programs for the interactive elicitation and cluster analysis of personal construct systems operating on a DECsystem 10 mainframe computer (Shaw, 1980). We have reported extensions to these that enable the logical relations within and between construct systems to be derived (Gaines \& Shaw, 1981). These programs have now been transferred to a microcomputer, the Apple II, available in many schools as an integrated suite for routine use (Shaw, 1982). This paper provides not only a rationale for the use of the techniques underlying these programs in education, but also an exposition of the role of personal construct psychology and Kelly's notions of constructive alternativism and the creativity cycle.

\section{Constructive alternativism}

The personal construct psychology of George Kelly (1955) provides the methodological framework for modelling a person's epistemological processes--his role as a personal scientist (Shaw, 1980) in coming to comprehend the world in idiosynchratic terms. However, as Kelly himself emphasizes, it goes very much beyond this in its implications for education by modelling the teachers in the same terms-as people whose construct systems are also changing as they interact with their students. For Kelly there was no correct framework of constructs but rather many alternative frameworks, inter-related in various ways, and each assessable as useful only with respect to some wider framework that itself was a system of constructs. He emphasizes constructive alternativ- 
ism as a basic philosophy for all knowledge acquisition in that we gain greater understanding of the world including the thought processes of ourselves and others by being able to use a number of different viewpoints and by being able to operate within a range of different construct systems.

Kelly rejected the notion of learning as a specific process to be studied in its own right. He regarded the attribution of phenomena in the behaviour of a particular individual to "learning" as being merely a convenient way of grouping information about their continually changing construct system and having no explanatory power. In the context of psychological experiments on learning he notes (Kelly, 1955, p. 77):

When a subject fails to meet the experimenter's expectations, it may be inappropriate to say that 'he has not learned'; rather, one might say that what the subject learned was not what the experimenter expected him to.... Let the experimenter find out what the subject is thinking about, rather than ask the subject to find out what the experimenter is thinking about.

In the context of education he saw learning as personal exploration and the teacher's role as helping "to design and implement each child's own undertakings. . . . To become a fully accredited participant in the experimental enterprise she must gain some sense of what is being seen through the child's eyes" (Kelly, 1970, p. 262). It is this capability for seeing through others eyes that must be programmed for the computer in individualizing instruction.

The wider significance of Kelly's personal construct psychology for educational studies has been emphasized by Pope \& Shaw (1981, p. 105) who note that "each of us have an implicit model of the learning process which will have an impact on our behaviour as a learner or teacher/trainer" and "educational ideologies embody theories of the nature and development of man". Pope \& Keen (1981, p. 34) in discussing the relation between Kelly's constructive alternativism and schools of education, note that

If one adopts this philosophy one can provide an adaptive educational system which assumes many ways of succeeding and multiple goals from which to choose ... in which individual learning styles are important and educational research is predicated on the individual's perspective. Constructive alternativism invites innovation and rejects dogma.

Thus personal construct psychology does not in itself provide a model of the learning process or of different approaches to the educational process. Rather it provides a framework for modelling different learning and educational processes in terms of the construct systems involved-the distinctions being made and the way in which they are valued. It sees the child's learning process as being a continuing, autonomous modelling of experience that happens, like other autonomic functions, without specific stimulation or control. It sees the educational process as providing experience to direct the child's learning process through interaction with a biassed environment. It sees the teacher as part of that environment providing exemplary constructs that are themselves changing and derived from other environments that reflect the constructs, and hence the values, of a particular educational system, culture and society.

Hence one may use the techniques of personal construct psychology not just to see the world through the child's eyes but also through the teacher's eyes, the headmaster's eyes, the school inspector's eyes, the College of Education lecturer's eyes, and so on. Each construct structure within one part of the system interfaces with, relates to, and 
is embedded within, construct structures in other parts of the system. Similar considerations apply to any social organization and there is an analogy in industry where the construct structures of workers, supervisors, managers and the managing director can each be investigated and their relationships analysed (Shaw, 1980, Ch. 9). With the availability of suitable programs on microcomputers now it is possible for similar studies to be carried out in schools, not just for research interest but as part of the process of increasing our understanding of, and hence the quality of, specific educational systems.

\section{Repertory grids}

In order to be able to see the world through another's eyes, Kelly developed the technique of using a repertory grid. He says (Kelly, 1955, p. 146):

think of constructs as providing ordinal axes in psychological space, the abscissas being provided by the temporal events themselves. With both constructs and events providing axes, the person builds a grid within whose quadrants his psychological space takes on multidimensional meaning. With respect to the ordinates there are many personal versions of what the axes are, but with respect to the abscissa of time we have a common experience.

His repertory grid is a way of presenting this personal psychological space by asking a person to rate elements of their experience in terms of their personal constructs.

Figure 1 shows a grid elicited from an architectural student where the elements of experience are photographs of public houses take by students as part of the course. The grid was elicited through interaction with the computer program PEGASUS (Shaw, 1980) that establishes a dialogue with the student and asks him to make distinctions between the elements, for example, "given these three elements in what way are two alike and different from the third". PEGASUS uses the availability of on-line computation to explore the student's psychological space thoroughly by asking him to make further distinctions based on his existing ones, for example, "you have so far failed to distinguish between these two elements-can you think of some way in which they differ'. Where the set of elements is not fixed PEGASUS also elicits additional elements by noting that two constructs are making very similar distinctions, for example, "you have so far used these two constructs in the same way-can you think of an element which is assigned to this pole on one and to the opposite pole on the other".

The grid shown in Fig. 1 has been analysed through the clustering program FOCUS (Shaw, 1980) which sorts it to bring together similar elements on one axis and similar constructs on the other. The two tree structures drawn above the grid for the elements and to the right-hand side for the constructs show the hierarchical groupings resulting from the clustering. Note that a rating of 1 means that the element is described by the left pole name, a rating of 5 means that the element is described by the right pole name, and intermediate rating values denote positions on the scale described by the two pole names. So from the tree on the right of Fig. 1 four major construct clusters can be distinguished. The most coherent contrasts those elements which are seen as havelock, bad, no atmosphere, styleless, and ugly with those which are olde worldy, good, atmosphere, stylish and pretty. The next cluster associates those seen as tasteless, disgust and pushing as against those which have taste, appeal and are secretive. A less 


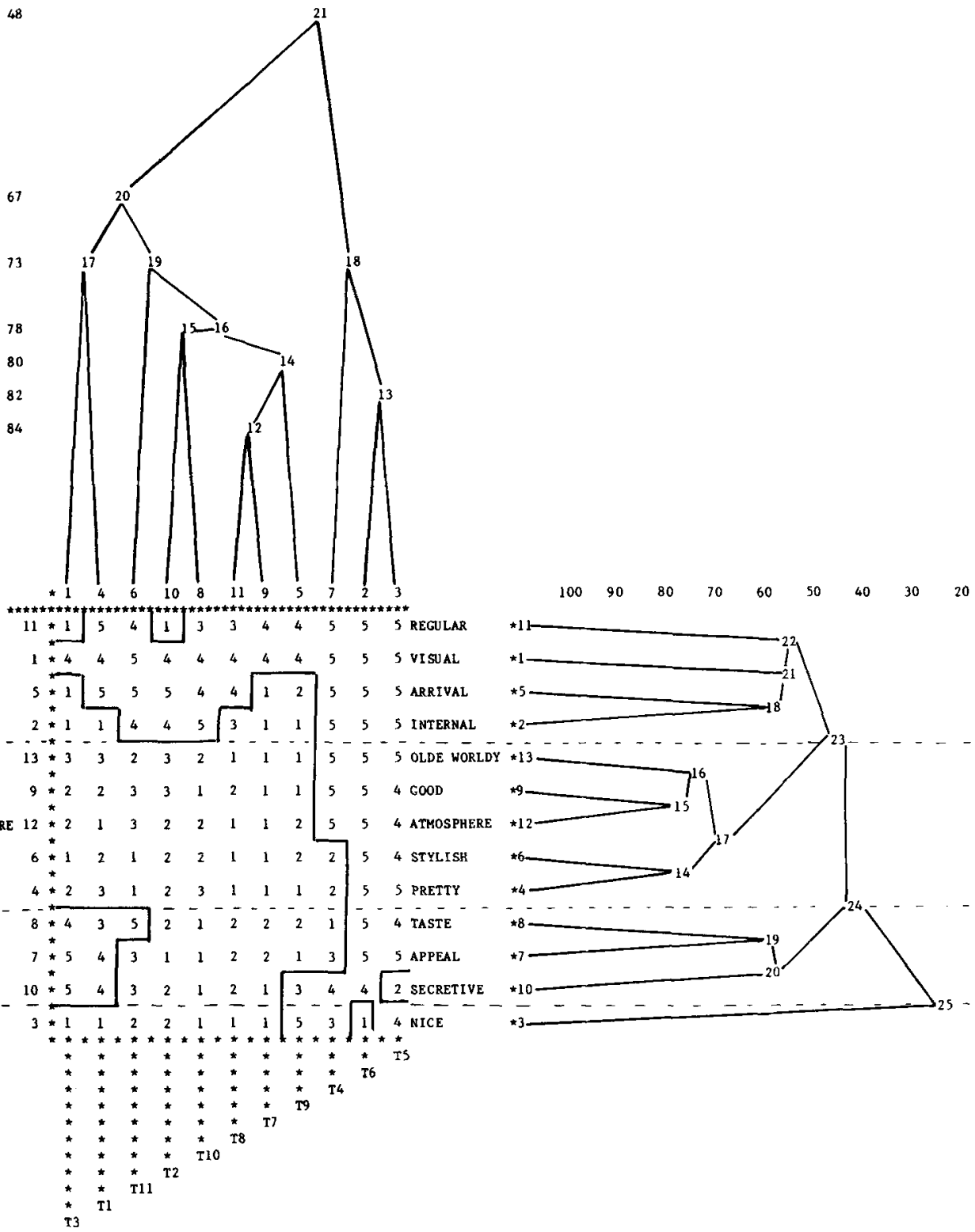

Fig. 1. FOCUSed grid from an architecture student on photographs of public houses.

tight cluster is shown by the top four constructs, and from the contour line separating the assignments to left and right poles it can be seen that this contains more complex distinctions. Finally, the construct nasty-nice is unrelated to any other construct clusters. Thus the student is able to see some of the interrelations between his constructs and how these derive from the distinctions he has made. 
Given the same set of elements it is possible to show in a FOCUSed grid of this sort the relations between constructs coming from different students. One can see them using different terms for the same distinctions, and also using the same terms for different distinctions. Figure 2 is a FOCUSed grid obtained by combining the grids from two different groups of art and design teachers each construing the same set of graphic computer programs. First, a brief description of the elements: BOUNCE is a program showing the use of randomness for change of colour, speed and direction of a bouncing object; PICASO is a complex graphics design system; 3D HOUSE is a perspective view of a line drawing of a house from various angles; YVETTE is a Prestel type of low resolution design of a woman's head; PICTURE is a program enabling composition of a picture from given basic shapes; APPLE PAD is the graphics

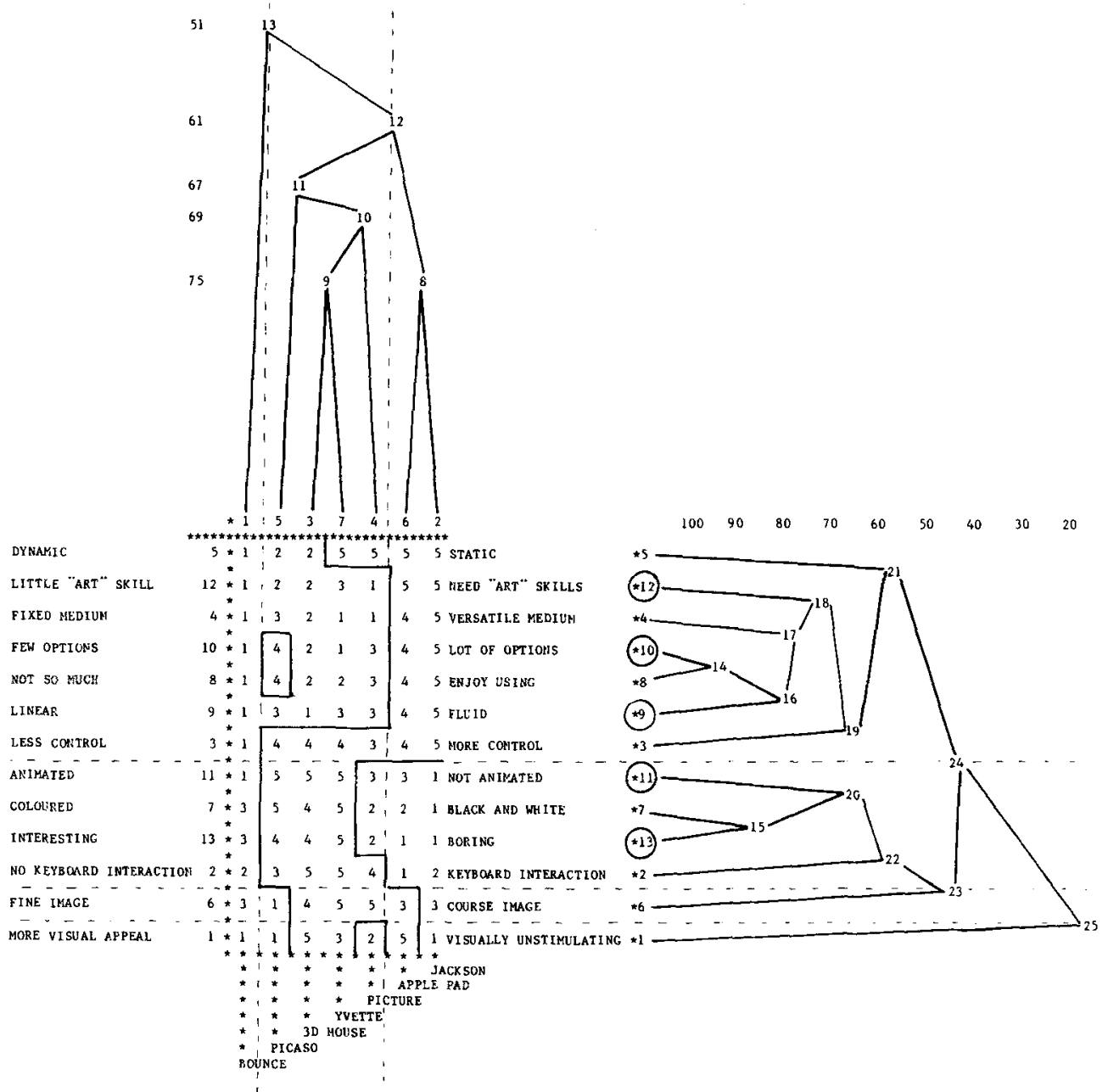

FIG. 2. Two grids FOCUSed together from art and design teachers on graphic computer progr:ms. 
tablet available as a peripheral to the Apple II; and JACKSON is a program to create pictures from a colour palette.

The constructs with a circle around the number are from one group and the uncircled constructs from the other. It can be seen that there are three main element clusters: (1), $(5,3,7$ and 4$)$ and (6 and 2$)$. There are four main construct clusters: $(5,12,4$, $10,8,9$ and 3$),(11,7,13$ and 2), (6) and (1). If we consider the top construct cluster first it is clear that the positively viewed descriptions are mainly on the right poles. Thus we see JACKSON and APPLE PAD as being highly rated with $4 \mathrm{~s}$ and $5 \mathrm{~s}$, BOUNCE being rated very low with 1 s and the middle element cluster rather more mixed. Looking now at the next construct cluster of 11, 7,13 and 2 the positive views are now located on the left poles. Thus JACKSON and APPLE PAD are again positively seen, the middle cluster is negatively seen (i.e. not animated, black and white, boring and using keyboard interaction), whilst BOUNCE has mixed views. The remaining two constructs at the bottom of the grid are each clusters in their own right, neither matching very highly with any other construct. That is, they are independent dimensions of thinking.

Now if we look at constructs from the two groups it is interesting to see how they relate to each other. For instance, cluster 14 shows that when one says lots of options the other is saying enjoy using: and cluster 15 shows that one group using coloured is similar to the other using interesting whilst black and white is boring. It is clear that the construct used by one group enjoy using-not so much is not like the other group's interesting-boring which one might have been led to expect. It is by examining the associations that these art and design teachers have when discussing these particular programs which could help us in designing new programs for use by art teachers. We can hypothesize that a colour monitor makes the programs more interesting, for example, or that exclusively keyboard interaction tends to be boring. Those programs which are most highly rated in this study are those which need art skills, have a versatile medium and lots of options; they are fluid and the user has more control over their use.

Thus PEGASUS and the associated FOCUS analysis can lead us to extract discriminations and associations which could not necessarily have been expressed as succinctly by the people concerned. Like children, computer naive people rightly expect the best of all worlds and judge a program not on its technical merits or its length, but on how it can stimulate interest and excitement, or enhance their own expertise in the job they are doing.

\section{The creativity cycle}

We have noted previously (Shaw \& Gaines, 1981) the problem of concentrating on the personal nature of construct systems without also accounting for their communal nature, at least in part. We live to a large extent in a shared real world about which we are able to communicate with one another. Whilst many constructs are personal and not meaningful to others, we must also have some constructs that enable us to share meaning with others. A major part of the educational process may be seen as an attempt to impart constructs that enable us to share meaning. These regions of shared meaning are often very specific, forming subject areas, in educational terms and we have called them worlds (Shaw \& Gaines, 1981) after Popper's (Schilpp, 1974) 
notion of a world 3 of "statements in themselves". A world 3 may be viewed on one hand as a product of human minds, as the consensual domain of shared meaning relating to a particular topic. However, particularly since it may be recorded in books independently of individual people, it also has an existence its own right as abstract, reified knowledge.

In these terms, Kelly's model of learning is that it occurs continually and that it is we, as observers, who construe it as learning in relation to our own construction of world 3s of abstract knowledge. He states (Kelly, 1955, p. 75) that learning

is not a special class of psychological processes; it is synonymous with all psychological processes ... not something that happens to a person on occasion; it is what makes him a person in the first place.

However, in education we are concerned with establishing an environment in which directed knowledge acquisition may take place--what we might term learning about a topic rather than just a general change in construing. Kelly discusses this in terms of the creativity cycle "which starts with loosened construction and terminates with tightened and validated construction" (Kelly, 1955, p. 528). If this validation is in relation to the constructions of others then we may see this cycle as one of creating shared meaning.

Note that sharing meaning does not necessarily involve sharing constructs. For example you may have a construct mean-generous that assigns Sam and Lucy as mean and Penny, Algernon, Nancy and Bert as generous. I may have no single construct that distinguishes these six people in this way. However, my construct has much money-has little money distinguishes Nancy, Sam, Algernon and Lucy as has much money from Bert and Penny as has little money. And my construct pays for others-paid for by others distinguishes Bert and Algernon as pays for others from Lucy, Nancy, Penny and Sam as paid for by others. Hence I can understand your term mean as has much money but paid for by others, that is, I can construct the distinction you are making from a combination of those that I make. This is not a symmetric relation because you cannot construct either of my distinctions above from yours given above without making further distinctions. Thus I may be able to use your term mean in the same way as you do without you being able to use my term corresponding to paid for by others.

For Kelly a loose construct is one in which the distinction being made is tentative and variable whereas a tight construct is one in which the distinction is firm and rigid (Kelly, 1955, p. 529). The creativity cycle is one in which the learner has loose constructs initially corresponding to his lack of knowledge, in the consensual domain sense, of the subject matter. He makes tentative distinctions and evaluates these against those of others, perhaps a teacher, and then gradually firms them up us he assesses that they are validated by leading to the same classifications as those of others. This is essentially a multistage process as can be seen by considering your teaching me your construct mean-generous, above. Initially my construing the individuals in these terms is totally loose and I would be happy to assign anyone to either pole of the construct. You might ask me to make a guess about the classification of Sam and Bert and tell me whether I am correct, or first note that Sam is mean but Bert is generous. I can then attempt to tighten my construction by looking for a construct that I have that differentiates Sam and Bert, for example that Sam is paid for by others but Bert pays for others. You now ask me whether Lucy is mean or generous 
and, noting that she is like Sam in being paid for by others, I classify her with Sam under your term mean. This is correct and my construction of your meaning has been validated by this example. You go on to ask me about Algernon and, noting that I class him with Bert, I say generous which you confirm. My construction is now well validated and I may regard it as tight-I have acquired your meaning.

However, now you ask about Penny and on the same basis I say mean which you say is wrong. I maay now take any number of courses such as arguing with you, giving up attempting to understand, asking for further examples, and so on. Eventually I may discover that the use of my additional construct has much money-has little money in conjunction with pays for others-paid for by others enables me to use your terms mean and generous in the same way as you do. At this stage I have a tight construction that will become tighter as I find more examples on which we agree. Of course, I never have any guarantee that a new example will not arise on which we disagree and for which I may have yet again to argue with you until one or other of us changes the basis of their construing.

Once construction has become tight through validation it can become loose again. The simple example above shows me coming to a validated construction matching yours using only two of my constructs in conjunction. It may well be that I achieve this with a rather more complex use of my constructs, validate it and tighten it as I become sure of it; but then go into a mode in which I look for a simpler use of my constructs to achieve the same effect. My construing will become tenative again and appear to loosen but it now corresponds to an attempt to find a simple, minimal, relation between our constructs that continues to be validated.

The tracking of this changing construction system and its relation to that of the teacher as a student learns seems to come closest a feasible "representation of each student's inferred knowledge state" called for in our introductory section. R. Smith (1976) has suggested a range of linguistic analyses and cognitive measures that may be seen as one approach to eliciting these systems in a practical way. Pope \& Keen (1981, p. 120) show how the FOCUS technique described earlier may be used to examine the changing construction of student teachers after teaching practice. Phillips (1981) has carried out a longitudinal study of the changing constructions of postgraduate students and their supervisors about their interaction with each other again using the FOCUS technique. The extension of FOCUS to multiple constructions of the same elements through the program SOCIOGRIDS (Shaw, 1980, 1981) seems to offer a particularly useful tool for tracking the creativity cycle. SOCIOGRIDS is normally used with different people and derives a social network showing their capabilities to use each other's construction systems. If it were used with the teacher and student at different stages of their mutual interaction then the social network would correspond to their learning trajectories in time in relation to each other. With the availability of such programs now on educational microcomputers it is feasible for such studies to come out of the research laboratory into the working environment of the classroom.

\section{Conclusions}

As microelectronics costs decrease, one can bring into the working educational environment tools for the exploration of a student's cognitive structures that were 
previously only available for research purposes. Such tools have little to do with the computer in its common stereotype as a fast numerical data processor but emphasize its educationally far more significant role of enabling expert systems to be used routinely to mimic human expertise. We have shown that the human expertise that goes into the elicitation of repertory grids can be emulated by computer programs on low-cost machines, and that the results of such elicitation can be analysed to show the construct system being used by the student to understand the subject matter being taught.

We have also argued, as have others, that Kelly's personal construct psychology from which this work derives is itself fundamentally important to our understanding the educational process and system, and that his notions of constructive alternativism and the creativity cycle give a practical framework for the individualization of teaching. In conclusion, we suggest that as new technologies make possible new approaches to education they also enable us to re-evaluate the underlying basis of the educational system, and require us to do so if we are to make effective use of them.

We would like to thank our colleagues in the Barbican Research Group for many hours of intense and fruitful discussion that have contributed to this paper.

\section{References}

Bobrow, D. G. \& Collins, A., Eds (1975). Representation and Understanding. New York: Academic Press.

BUNDERSON, C. V. (1974). The design and production of learner-controlled courseware for the TICCIT system: a progress report. International Journal Man-Machine Studies, 6 (4), 479-491.

FAHLMANN, S. E. (1979). NETL: A System for Representing and Using Real-World Knowledge. Cambridge, Massachusetts: M.I.T. Press.

GAINES, B. R. (1978). Man-computer communication-what next? International Journal of Man-Machine Studies, 10 (3), 225-232.

GAINES, B. R. \& SHAW, M. L. G. (1981). New directions in the analysis and interactive elicitation of personal construct systems. In SHAW, M. L. G., Ed., Recent Advances in Personal Construct Technology, pp. 147-182. London: Academic Press.

GALANTER, E. (1959). The ideal teacher, In GALANTER, E., Ed., Automatic Teaching: The State of the Art, pp. 1-11. New York: John Wiley.

Kelly, G. A. (1955). The Psychology of Personal Constructs. New York: W. W. Norton.

Kelly, G. A. (1970). Behaviour as an experiment. In BANNISTER, D., Ed., Perspectives in Personal Construct Theory, pp. 255-269. London: Academic Press.

LumSDAINE A. A. \& GlASER, R., Eds (1960). Teaching Machines and Programmed Learning. Washington, D.C.: National Education Assocation of the United States.

MichIE, D., Ed. (1979). Expert Systems in the Micro Electronic Age. Edinburgh University Press.

MITCHELL, P. D. (1981). Representation of knowledge in CAL courseware. In SMITH, P. R., Ed., Computer Assisted Learning, pp. 61-66. Oxford: Pergamon Press.

PHILlipS, E. M. (1981). Education for research: the changing constructs of the postgraduate. In SHAw, M. L. G., Ed., Recent Advances in Personal Construct Psychology, pp. 95-104. London: Academic Press.

POPE, M. L. \& KeEN, T. R. (1981). Personal Construct Psychology and Education. London: Academic Press.

POPE, M. L. \& SHAw, M. L. G. (1981). Personal construct psychology in education and learning. In SHAw, M. G. L., Ed., Recent advances in Personal Construct Technology, pp. 105-114. London: Academic Press.

SCHILPP, P. A., Ed. (1974). The Philosophy of Karl Popper. Illinois: Open Court. 
SHAw, M. L. G. (1980). On Becoming a Personal Scientist: Interactive Computer Elicitation of Personal Models of the World. London: Academic Press.

SHAw, M. L. G., Ed. (1981). Recent Advances in Personal Construct Psychology. London: Academic Press.

SHAW, M. L. G. (1982). The PLANET suite: programs for repertory grid elicitation and analysis. International Journal of Man-Machine Studies (to appear).

SHAW, M. L. G. \& GAINES B. R. (1981). The personal scientist in the community of science. In RECKMEYER, W. J., Ed., General Systems Research and Design: Precursors and Futures, pp. 59-68. Kentucky: Society for General Systems Research.

SLEEMAN, D. H. \& BROWN, J. S., Eds (1982). Intelligent Tutoring Systems. London: Academic Press.

SMITH, P. R., Ed. (1981). Computer Assisted Learning. Oxford: Pergamon Press.

SMITH, R. A. (1976). Computer-based structural analysis in the development and administration of educational materials. International Journal of Man-Machine Studies, 8 (4), 439-463.

SUPPES, P. (1967). On using computers to individualize instruction. In BuSHNELL, D. D. \& Allen, D. W., Eds, The Computer in American Education, pp. 11-24. New York: John Wiley.

TAGG, E. D., Ed. (1980). Microcomputers in Secondary Education. Amsterdam: North-Holland. 